\title{
Prevalence of Bovine Babesiosis and Theileriosis in Kerala, India
}

\section{Pradeep R. Kariyappa ${ }^{1}$, Reghu Ravindran ${ }^{1 *}$, Murikoli Nimisha ${ }^{1}$, Birur Mallappa Amrutha ${ }^{1}$, Prashant Somalingappa Kurbet ${ }^{1}$, Karapparambu Gopalan Ajith Kumar ${ }^{1}$, Anju Varghese ${ }^{1}$, Chundayil Kalarikkal Deepa ${ }^{1}$ and Chemmangattuvalappil Narendranath Dinesh ${ }^{2}$}

${ }^{1}$ Department of Veterinary Parasitology, College of Veterinary and Animal Sciences, Pookode, Lakkidi, P.O., Wayanad-673576, Kerala, India

${ }^{2}$ Department of Animal Genetics and Breeding, College of Veterinary and Animal Sciences, Pookode, Lakkidi, P.O., Wayanad-673576, Kerala, India

*Corresponding author

\section{A B S T R A C T}

\section{Keywords}

Babesia bigemina,

Theileria orientalis,

Prevalence, Cattle,

Kerala.

Article Info

Accepted:

21 June 2017

Available Online:

10 August 2017
The prevalence of bovine babesiosis and theileriosis in northern, middle and southern regions of Kerala was studied. A total of 246 apparently normal/healthy crossbred adult cattle blood smears were screened by microscopy after Giemsa's staining. Among 246 animals screened, 26.82 per cent were positive for Theileria orientalis and 8.13 per cent were positive for Babesia bigemina. The present study revealed, higher prevalence of $T$. orientalis in northern Kerala (40 per cent) and middle Kerala (39.28 per cent), whereas $B$. bigemina was highly prevalent in southern Kerala (14.94 per cent).

\section{Introduction}

India is an agricultural country and over 70 per cent of rural households depend on livestock farming for supplementary income. Livestock population in India is threatened by infectious disease outbreaks, floods, draught and other climatic factors. Infectious diseases cause morbidity, mortality, reduced body weight gain, decreased draught power, decreased production (milk, meat, wool) and fertility thereby collectively causing economic losses to the livestock and dairy industry (Saminathan et al., 2016). Among the various infectious diseases, parasitic diseases cause significant effect on growth and production of animals.
Among the top ten diseases of livestock reported from thirty states of the country (Annual report 2014-15, NIVEDI), five were parasitic diseases, viz., facsiolosis, coccidiosis, trypanosomosis, babesiosis and theileriosis. Bovine babesiosis and theileriosis are the tick transmitted haemoprotozoan diseases in India which are considered economically most important. The annual control cost for tick and tick borne diseases (TTBDs) of livestock in India was approximately US\$ 498.7 million, which included 384.3 million US\$ for Theileria annulata and 57.2 million US\$ for babesiosis (Minjauw and Mc Leod, 2003). 
The early diagnosis of haemoprotozoan diseases and proper treatment may reduce the mortality and losses. The diagnosis of babesiosis and theileriosis in acute cases is mainly based on clinical findings and microscopic examination of thin blood smears. Hence, an attempt was made in the present study to find prevalence of tick borne haemoprotozoan diseases of cattle in Kerala.

\section{Materials and Methods}

A total of 246 apparently normal / healthy crossbred adult cattle (Jersey/Holstein Fresian/Swiss Brown) from three different regions of Kerala viz., northern (Wayanad, $\mathrm{n}=106$ ), middle (Thrissur, $\mathrm{n}=28$ ) and southern region (Idukki, $\mathrm{n}=87$ and Thiruvananthapuram, $\mathrm{n}=25$ ) were screened for haemoprotozoan parasites.

Two thin blood smears were made from the ear vein of each animals and air dried. The blood smears were fixed with methanol for 5 minutes and stained with Giemsa's stain for 30 minutes. Stained thin blood smears were examined microscopically for protozoan parasites under the oil immersion (100 X magnification) objective of the microscope.

Even the presence of single piroplasm was considered as a positive case and a minimum of 5000 red blood cells (RBCs) were screened before proclaiming negative for any blood parasites.

\section{Results and Discussion}

Results of the screening of blood smears by microscopy after Giemsa's staining are shown in table 1 . Among the 246 cattle screened by microscopy, 86 (34.95 per cent) were positive for haemoprotozoan parasites. Out of 246 cattle samples screened, 26.82 per cent were positive for Theileria orientalis and 8.13 per cent were positive for Babesia bigemina.
In all the positive smears screened, theilerial piroplasms were observed with different morphological appearances. They were intraerythrocytic thin and thick rod shaped or annular piroplasms (Fig. 1).

The Babesia organisms were discerned as paired pear shaped or single pear shaped piroplasms or single oval/irregularly shaped amoeboid forms within the RBCs (Fig. 2).

The haemoprotozoan diseases in cross-bred cattle are the major constraints for livestock development which causes devastating losses to the livestock and dairy industry throughout the world. The bovine babesiosis caused by $B$. bigemina and theileriosis by $T$. annulata and $T$. orientalis are the important tick borne haemoprotozoan diseases in the tropical and subtropical countries of the world including India.

Previously, Trypanosoma evansi, B. bigemina and Theileria species were identified as the major haemoprotozoan organisms of cattle in Northern Kerala (Nair et al., 2011). Later Theileria orientalis was identified as the organism causing fatal disease in crossbred adult cattle of Wayanad district of Kerala, South India (Aparna et al., 2011). Aparna et al., (2013) conducted phylogenetic analysis of the field populations of $T$. orientalis and identified types 1, 3 and 7 from Kerala.

Similarly, a high seroprevalence of 67.6 per cent was recorded for B. bigemina (Ravindran et al., 2002) using indirect fluorescent antibody test (IFAT) and 70.9 per cent using SELISA (Ravindran et al., 2007).

The present study revealed low prevalence status (3.77 per cent) for B. bigemina in Wayanad, a northern district of Kerala. Very high prevalence status for the same parasite was observed in Idukki (14.94 per cent), a southern district of Kerala. 
Table.1 Results of blood smears screening by microscopy after Giemsa's staining

\begin{tabular}{|l|l|l|l|}
\hline Place of collection & $\begin{array}{l}\text { Number of samples } \\
\text { examined }\end{array}$ & Theileriaorientalis & $\begin{array}{l}\text { Babesia } \\
\text { bigemina }\end{array}$ \\
\hline Wayanad & 106 & $43(40 \%)$ & $4(3.77 \%)$ \\
\hline Idukki & 87 & $7(8.04 \%)$ & $13(14.94 \%)$ \\
\hline Thrissur & 28 & $11(39.28 \%)$ & $2(7.14 \%)$ \\
\hline Thiruvananthapuram & 25 & $5(20 \%)$ & $1(4 \%)$ \\
\hline Total & $\mathbf{2 4 6}$ & $\mathbf{6 6}$ & $\mathbf{2 0}$ \\
\hline
\end{tabular}

Fig.1 Theileria orientalis in bovine blood smear (1000X)

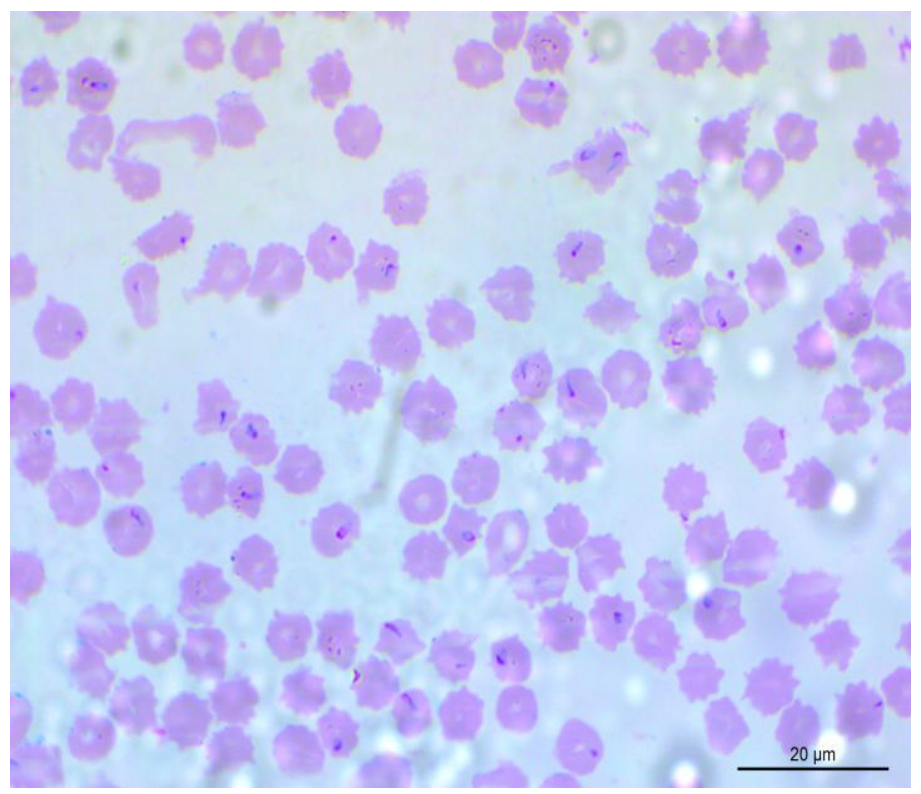

Fig.2 Babesia bigemina in bovine blood smear (1000X)

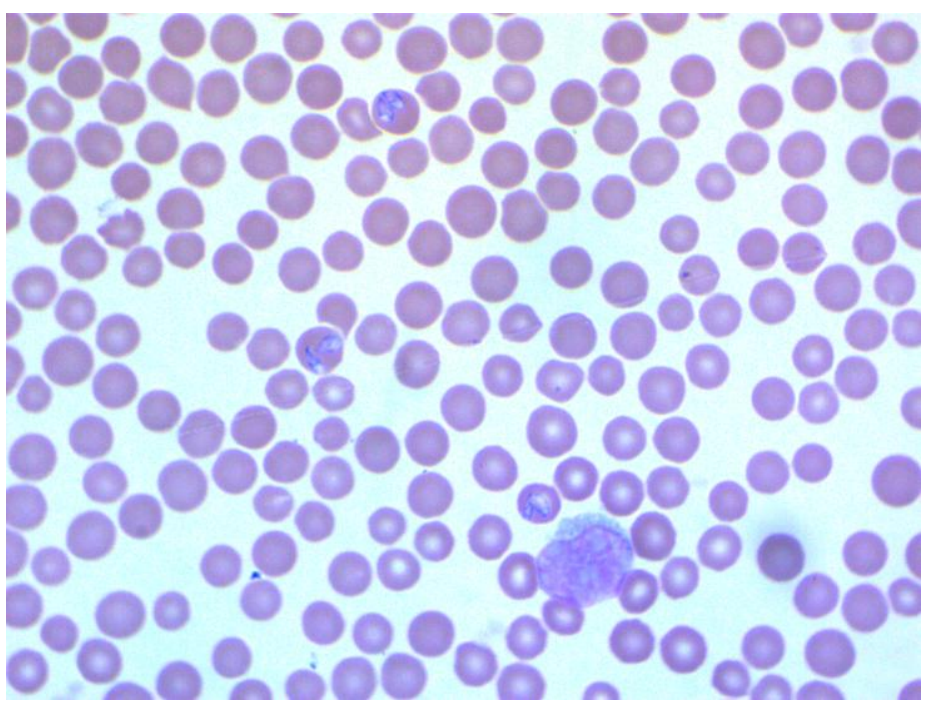


Previously, different per cent prevalence rates for of babesiosis in Kerala based on blood smear examination viz., 2.66 (from Northern Kerala: Nair et al., 2011), 12.5 (from Ernakulum and Thrissur Central Kerala: Rejitha, 2003) were recorded. In addition, prevalence rate of 22.83 per cent from Gujarat (Maharana et al., 2016), 0.25 to 8.33 per cent from Punjab (Aulakh et al., 2005; Sharma, 2013; Singh et al., 2013), 0.6 to 16 per cent from Karnataka (Muraleedharan, 2015), 1.3 per cent from Maharastra (Kolte et al., 2017) were also reported for $B$. bigemina.

In the present study, a high prevalence status for Theileria orientalis from Wayanad (40.57 per cent) and Thrissur (39.28 per cent) districts, whereas low prevalence status from Idukki (8.04 per cent) districts were observed. Previously, a per cent prevalence of 33.33 from Wayanad (Aparna, 2011) and 40.66 from Northern districts of Kerala (Nair et al., 2011) were reported for T. orientalis.

The present study suggests that Kerala is endemic for theileriosis due to $T$. orientalis and babesiosis in bovines. There is a need for further investigation and identification of carrier status of babesiosis using molecular techniques.

\section{Acknowledgements}

Authors are grateful to all the Veterinary Surgeons, Animal Husbandry Department, Kerala who kindly provided help in collection of samples. Financial supports from Indian Council of Agricultural Research through research projects (NAIP/Com-4/C2066/20072008, NFBSFARA/BSA-4004/2013-14, NASF/ABA-6015/2016-17, No.7 (2)/- 2011- EPD), Department of Animal Husbandry, Kerala (B2-8401/08/Plg) and Kerala State Council for Science, Technology and Environment (022/YIPB/ KBC/2013/CSTE， 010-14/SARD/13/CSTE) are thankfully acknowledged.

\section{References}

Annual report, National Institute of Veterinary Epidemiology and Disease Informatics (NIVEDI-ICAR) 2014-15. Bengaluru. 47p.

Aparna, M. 2011. Molecular characterization of theilerial piroplasms in cattle of Wayanad. MVSc thesis, Kerala Veterinary and Animal Sciences University, Pookode, Wayanad. 52p.

Aparna, M., Ravindran, R., Vimalkumar, M. B., Lakshmanan, B., Rameshkumar, P., Ajith Kumar, K. G., Promod, K., Ajithkumar, S., Ravishankar, C., Devada, K., Subramanian, H., George, A. J. And Ghosh, S. 2011. Molecular characterization of Theileria orientalis causing fatal infection in crossbred adult bovines of South India. Parasitol. Int., 60(4): 524-529.

Aparna, M., Vimalkumar, M. B., Varghese, S., Senthilvel, K., Ajithkumar, K. G., Raji, K., Syamala, K., Priya, M. N., Deepa, C. K., Jyothimol, G., Juliet, S., Chandrasekhar, L. and Ravindran, R. 2013. Phylogenetic analysis of bovine Theileria Spp. isolated in South India. Trop. BioMed., 30(2): 281-290.

Aulakh, G. S., Singla, L. D., Kaur, P. and Alka. 2005. Bovine babesiosis due to Babesia bigemina: haematobiochemical and therapeutic studies. Indian J. Anim. Sci., 75: 617-622.

Kolte, S. W., Larcombe, S. D., Jadhao, S. G., Magar, S. P., Warthi, G., Kurkure, N. V., Glass, E. J. and Shiels, B. R. 2017. PCR diagnosis of tick-borne pathogens in Maharashtra state, India indicates fitness cost associated with carrier infections is greater for crossbred than native cattle breeds. PLOS ONE. 12(3). http://dx.doi.org/10.

1371/journal.pone.0174595

Maharana, B. R., Kumar, B., Prasad, A., Patbandha, T. K., Sudhakar, N. R., Joseph, J. P., and Patel, B. R. 2016. 
Prevalence and assessment of risk factors for haemoprotozoan infections in cattle and buffaloes of South-West Gujarat, India. Indian J. Anim. Res., 50 (5): 733-739.

Minjauw, B. and McLeod, A. 2003. The impact of ticks and tick borne diseases on livelihood of small scale and marginal livestock owners in India and eastern and south Africa. In: Tick borne diseases and poverty research report, DFID Animal Health Programme, Center for Tropical Veterinary Medicine, University of Edinburgh, U.K. 124p.

Muraleedharan, K. 2015. Babesia and babesiosis in livestock of Karnataka state, India- an overview. Vet. Res. Int., 3: 81-82.

Nair, A. S., Ravindran, R., Lakshmanan, B., Kumar, S. S., Tresamol, P. V., Saseendranath, M. R., Senthilvel, K., Rao, J. R., Tewari, A. K. and Ghosh, S. 2011. Haemoprotozoa of cattle in Northern Kerala, India. Trop. Biomed., 28(1): 68-75.

Ravindran, R., Mishra, A. K. and Rao, J. R. 2002. On the high seroprevalence of bovine babesiosis in Wynad district of Kerala. J. Appl. Anim. Res., 22: 43-48.

Ravindran, R., Mishra, A. K. and Rao, J. R. 2007. Slide enzyme-linked immunosorbent assay for the diagnosis of Babesia bigemina infection in bovines. Vet. Res. Commun., 31: 9991004.

Rejitha, T. S. 2003. Evaluation of different techniques for the diagnosis of bovine babesiosis. MVSc thesis, Kerala Agricultural University, Thrissur. 74p.

Saminathan, M., Rana, R., Ramakrishnan, M. A., Karthik, K., Malik, Y. S. and Dhama, K. 2016. Prevalence, diagnosis, management and control of important diseases of ruminants with special reference to Indian scenario. J. Exp. Biol. Agric. Sci., 4(3S): 338-367.

Sharma, A., Singla, L. D., Tuli, A., Kaur, P., Batth, B. K., Javed, M. and Juyal, P. D. 2013. Molecular prevalence of Babesia bigemina and Trypanosoma evansi in dairy animals from Punjab, India, by duplex PCR: A step forward to the detection and management of concurrent latent infections. Bio Med. Res. Int. 2013: ID 893862, 8 pages. (http://dx.doi.org/10.1155/2013/893862 )

Singh, H., Jyoti, Haque, M., Singh N. K., and Rath S. S. 2013. PCR based detection of subclinical bovine babesiosis in Punjab. Indian J. Anim. Res., 47 (6): 543-546.

\section{How to cite this article:}

Pradeep R. Kariyappa, Reghu Ravindran, Murikoli Nimisha, Birur Mallappa Amrutha, Prashant Somalingappa Kurbet, Karapparambu Gopalan Ajith Kumar, Anju Varghese, Chundayil Kalarikkal Deepa and Chemmangattuvalappil Narendranath Dinesh. 2017. Prevalence of Bovine Babesiosis and Theileriosis in Kerala. Int.J.Curr.Microbiol.App.Sci. 6(8): 2310-2314. doi: https://doi.org/10.20546/ijcmas.2017.608.272 